\title{
The adaptation of cold-tolerant sorghum and maize to different environments in the highlands of Kenya
}

\author{
H. van Arkel
}

UNDP/FAO Kenya Sorghum and Millets Development Project, P.O. Box 1275, Nakuru, Kenya *

Accepted: 15 March 1980

Key words: sorghum, cold tolerance, highlands, maize, forage yield, grain yield. yield stability, time of planting, altitude, rainfall, temperature, environmental index

\section{Summary}

Two new introductions of high altitude sorghum, one a grain type and the other a forage type and two maize cultivars were tested in a number of trials during 1974, 1975, 1976 and 1977 in the highlands of Kenya. Yield data were regressed on altitude, rainfall and some data on temperature. Altitude had no significant effect on either grain or forage yield of any crop over the range tested which varied from 1525 to $2593 \mathrm{~m}$. Yields were positively correlated with rainfall and negatively with temperature. The grain sorghum benefited less from increased rainfall and also suffered less from reduced rainfall than any other entry. There were indications that the same grain type sorghum was more sensitive to temperature than any other entry.

The interaction between genotypes and environments was considered more important than the crop yield averages. For an accurate estimate of this interaction the yield stability analysis, whereby yields are regressed on the environmental index, proved essential. Although rainfall was the most important factor affecting crop yields, it only explained about $50 \%$ of the yield differences, whereas the index accounted for $90 \%$ or more of the yield differences.

The grain sorghum was the highest yielding grain crop at low and medium rainfall levels, but this was only partly due to its superior water use efficiency and mainly to a more favourable dry matter (DM) distribution. The forage sorghum was the highest DM yielding entry under most conditions. The maize cultivars outyielded the sorghums only if growing conditions were good. Where rainfall was high $(>1000 \mathrm{~mm}$ ) DM yields of all crops were lower than where rainfall was from 800 to $1000 \mathrm{~mm}$. Particularly sorghum yields were reduced at high rainfall

* Present address: UNDP/FAO Egyptian Beef Industry Development Project, P.O. Box 1893, Alexandria, Egypt 
giving the maize a distinct advantage. But it was not clear whether this yield effect was due to rainfall per se or to temperature differences.

\section{Introduction}

The search for forage crops suitable for cultivation in the relatively drier areas above $1500 \mathrm{~m}$ elevation in Kenya formed part of a project jointly sponsored by the Kenya Government, UNDP and FAO (who all provided funds or facilities). A number of species and varieties were tested in 1974 (van Arkel, 1977), among which were some sorghum collections from the highlands of Southwest Uganda and Central Ethiopia. In the first screening nurseries some of these high altitude sorghums outyielded maize. Essentially, it was immediately apparent that whereas sorghums originating from lowland areas were slow growing and susceptible to leaf and panicle diseases, the high altitude cultivars were relatively free from disease and were vigorous in their growth. No information regarding optimum crop husbandry or response to different environments using this newly identified germplasm was available, and an agronomy programme was mounted to gain a deeper understanding of the specific requirements for a successful cultivation of the crop (van Arkel, 1978a, b, c, 1979, 1980). At the same time a number of new sorghum lines were selected for further regional testing in subsequent years.

In the highlands of Kenya considerable differences in average annual rainfall and temperature and in soil conditions occur over short distances. Furthermore, total annual rainfall usually varies widely around the long term average. This leads to a wide range of environmental conditions in the highlands and it is desirable to know the relative expected yield performance of various crops. This will facilitate agricultural planning and enable farmers to minimize their cropping risks. To evaluate these aspects, this paper examines the yield potential of two of the high altitude sorghum cvs and two maize cvs by analysing the yield data of four years of crop testing nurseries. Special attention is paid to the relative reaction of the sorghum and maize cultivars to altitude, rainfall and temperature differences; and to the causes of grain yield differences.

\section{Materials and methods}

\section{Nurseries and trials}

The yield data used in this study were taken from the regional sorghum test nurseries in 1974, 1975 and 1976 and from a 'time of planting' experiment in 1977. The experimental procedures and results of the 1974 trials were reported by van Arkel (1977) and for the 1975 trials by Enserink (1976). All regional trials were laid down as completely randomised block designs with three replications, which were all planted immediately after the onset of the rains. The only exception was the trial at Kitale in 1975 which was planted on 15 May, about six weeks after the rainy season had started. The total number of genotypes in the trials was progressively reduced from 216 in 1974 to 21 in 1975 and to 4 in 1976 . But the number of test sites was increased from 3 in 1974 to 9 in 1975 and 21 in 
1976. For reasons of resource availability it had to be decided to discontinue the regional trials in 1977. Instead a 'time of planting' experiment with the same four genotypes as in the 1976 regional trial and with six planting dates was carried out at two distinctly different trial sites. This provided 12 additional environments and the details of this experiment were reported by van Arkel (1980).

The results of eight regional trials were excluded from the analysis because the yield data were mistrusted. This was due to either excessive bird or game damage, to inadequate germination, to severe sorghum shootfly damage or to uncontrolled irrigation.

Consequently, 37 test environments remained for analysis. The elevation of the sites ranged from 1525 to $2593 \mathrm{~m}$ above sea level. The rainfall ranged from $155 \mathrm{~mm}$ to $1305 \mathrm{~mm}$ during the field period of the test crops which compared with a range of $255 \mathrm{~mm}$ to $1850 \mathrm{~mm}$ of total annual rainfall.

\section{Genotypes}

Out of the 85 high altitude sorghum collections which were brought to Kenya in 1973, 25 were selected to be included in the 1974 nurseries. The following year this was reduced to nine lines. With the performance data of three years it then became clear that there was one line to be preferred above all others for total dry matter (DM) yield potential and one for grain yield potential. The code number for the former is ' $\mathrm{E} 6518$ ' which will be referred to as the forage sorghum and the code number of the latter is ' $\mathrm{E}$ 1291' which will be referred to as the grain sorghum. The forage sorghum - when grown in the Lanet area under good conditions - matures in approximately 215 days and can grow up to a height of about $3.5 \mathrm{~m}$. The grain sorghum grown in the same area will mature in about 165 days and reaches a height of about $1.6 \mathrm{~m}$.

The two maize cultivars used were the commercial hybrid ' $\mathrm{H}$ 613' and 'Local Yellow', a Kenya adapted open pollinated selection which is said to be able to outyield the hybrids if growing conditions become unfavourable. A more detailed description of the pedigree and yield performance potential of ' $\mathrm{H} 613$ ' can be obtained from Darrah \& Penny (1974) and Darrah (1976). 'H 613' appeared as one of the highest maize grain yielding entries in East Africa when grown above $1600 \mathrm{~m}$. But also in maize trials for total forage production ' $\mathrm{H}$ 613' regularly ranked as one of the highest total DM yielding entries (Sheldrick, 1974).

\section{Statistical analysis}

The genotype environment interaction was studied by means of a yield stability analysis, where the yield data of each genotype were regressed in a linear model on the 'environmental index'. The latter was obtained by subtracting the grand mean yield of all genotypes over all environments from the mean yield of all genotypes at any one environment. This method was first introduced by Yates \& Cochran (1938), later used by Finlay \& Wilkinson (1963) and refined by Eberhart \& Russell (1966). For the examination of significant differences between the regression lines the above method was modified again, as proposed by Freeman \& 
Perkins (1971). The modification was made by taking a different set of yield data to constitute the independent variable in the regression model. The 'environmental index' was computed as above, but only the yield data of one replicate were used. The average yield of the other two replicates was then regressed on to the environmental index. This modification was needed to satisfy the statistical requirement of regression analysis models. To analyse the probability levels for differences between regression lines, the Newman-Keuls test as published by Zar (1974) was used.

To visualize the genotype environment interaction, the regression lines were shown in a diagram with one section for total DM yield and one section for grain yield. To allow a comparison between the total DM yield and grain yield reaction of a genotype to environmental differences, the total DM yields and grain yields were regressed on a common base: the 'relative environmental index'. The difference between this and the conventional environmental index is that the relative index is expressed in percentage yield deviation from the mean instead of a deviation expressed in weight per ha.

\section{Results}

\section{Effects of altitude, rainfall and environmental index}

The yield data (Table 1) were grouped into three categories as follows: (I) Environments where rainfall was under $1000 \mathrm{~mm}$ and where the crops were planted early. (II) The time of planting trials where crops were planted at progressively longer intervals after the start of the wet season, but where rainfall was always under $1000 \mathrm{~mm}$. (III) Environments where rainfall was above $1000 \mathrm{~mm}$.

Crop yields were not significantly correlated with altitude (data not shown) regardless of whether data were analysed separately in group I and III or whether they were pooled. However, altitude had a significant effect on rainfall $(\mathrm{P}<0.01)$ and explained $38 \%$ of all rainfall differences of all sites in group I and III. Data from group II were excluded from the above analyses because they were obtained from only two different sites and rainfall differences and yield differences could therefore not be related to altitude.

The yield data of group I and II were separately regressed on rainfall (Fig. 1), which showed that there was a linear yield increase with increased rainfall for all crops. For total DM yield in group I, the grain sorghum was the top yielding entry under the very driest conditions. But under all other conditions the forage sorghum was the highest yielding entry, although the difference with maize ' $\mathrm{H} 613$ ' became smaller and smaller as rainfall increased. For grain yield in group I, the grain sorghum was the top yielder if rainfall was under $640 \mathrm{~mm}$ and maize ' $\mathrm{H} 613$ ' outyielded all other entries if rainfall exceeded $640 \mathrm{~mm}$.

The yield levels in group II were lower than in group I at comparable rainfall levels. This was possibly due to below average soil conditions or to a less favourable rainfall distribution. However, the more interesting difference between group I and II was the slope of the regression lines, which can more easily be seen 
H. VAN ARKEL

Table 1. Total DM yield and grain yield for two sorghum and two maize cultivars grown at 37 different environments where rainfall was recorded.

\begin{tabular}{|c|c|c|c|c|c|c|c|c|c|c|}
\hline \multirow[t]{2}{*}{ Year } & \multirow[t]{2}{*}{ Location } & \multicolumn{4}{|c|}{ Total DM yield $(1000 \mathrm{~kg} / \mathrm{ha})$} & \multicolumn{4}{|c|}{ Grain yield $(1000 \mathrm{~kg} / \mathrm{ha})$} & \multirow{2}{*}{$\begin{array}{l}\text { Rain- } \\
\text { fall } \\
\text { (mm) }\end{array}$} \\
\hline & & 'E 6518' & 'E 1291' & 'H 613' & $\begin{array}{l}\text { 'Local } \\
\text { Yellow' }\end{array}$ & 'E 6518' & 'E 1291' & 'H 613' & $\begin{array}{l}\text { 'Local } \\
\text { Yellow' }\end{array}$ & \\
\hline 1974 & Lanet 1 & 25.8 & 17.2 & 23.6 & 18.4 & 3.7 & 7.3 & 7.0 & 5.8 & 810 \\
\hline 1974 & Lanet 2 & 19.5 & 11.1 & 17.6 & 17.4 & 4.0 & 4.8 & 5.8 & 3.8 & 720 \\
\hline 1975 & Katumani & 1.2 & 2.9 & 0.9 & 1.6 & 0.0 & 0.4 & 0.0 & 0.2 & 170 \\
\hline 1975 & Naivasha & 17.5 & 10.8 & 18.3 & 14.0 & 2.8 & 5.0 & 5.9 & 5.0 & 420 \\
\hline 1975 & Lanet 1 & 29.0 & 17.3 & 30.1 & 24.2 & 7.0 & 7.2 & 9.0 & 6.4 & 783 \\
\hline 1975 & Lanet 2 & 17.4 & 8.1 & 17.1 & 17.5 & 5.0 & 3.3 & 5.2 & 5.7 & 645 \\
\hline 1975 & Kitale & 11.7 & 6.6 & 21.6 & 18.5 & 1.3 & 1.9 & 7.8 & 7.4 & 1050 \\
\hline 1975 & Baraton & 9.9 & 7.2 & 17.3 & 14.8 & 3.0 & 1.6 & 7.3 & 7.4 & 1200 \\
\hline 1976 & T. Falls & 6.4 & 6.4 & 4.0 & 4.4 & 0.0 & 2.5 & 0.4 & 0.8 & 250 \\
\hline 1976 & Njoro & 17.0 & 11.8 & 16.0 & 13.0 & 3.6 & 5.1 & 4.8 & 4.1 & 500 \\
\hline 1976 & Katumani & 4.2 & 5.1 & 2.4 & 3.3 & 0.0 & 1.6 & 0.0 & 0.3 & 190 \\
\hline 1976 & Lanet 1 & 15.5 & 11.2 & 14.4 & 11.8 & 3.0 & 4.7 & 4.1 & 3.7 & 489 \\
\hline 1976 & Lanet 2 & 8.5 & 7.5 & 6.4 & 6.0 & 0.4 & 2.9 & 1.1 & 1.6 & 433 \\
\hline 1976 & Rumuruti & 8.1 & 7.3 & 6.0 & 5.8 & 0.1 & 2.3 & 0.7 & 1.4 & 250 \\
\hline 1976 & Elmenteita & 12.8 & 9.7 & 11.2 & 9.5 & 1.0 & 4.0 & 2.9 & 2.9 & 455 \\
\hline 1976 & Embu & 23.1 & 15.1 & 23.1 & 18.1 & 5.0 & 6.0 & 6.5 & 5.4 & 805 \\
\hline 1976 & Rongai & 16.4 & 12.1 & 17.4 & 13.4 & 3.5 & 5.1 & 4.8 & 4.2 & 505 \\
\hline 1976 & Thika & 24.2 & 15.7 & 24.5 & 19.0 & 5.5 & 6.4 & 6.8 & 5.6 & 825 \\
\hline 1976 & Kiambu & 22.0 & 14.5 & 21.6 & 17.2 & 4.8 & 6.1 & 6.4 & 5.2 & 695 \\
\hline 1976 & Solai & 25.1 & 16.5 & 25.5 & 19.5 & 5.5 & 6.5 & 7.2 & 5.9 & 845 \\
\hline 1976 & Gilgil & 3.5 & 4.8 & 0.9 & 1.9 & 0.0 & 1.2 & 0.0 & 0.0 & 155 \\
\hline 1976 & Naivasha & 10.5 & 8.7 & 8.7 & 7.7 & 0.9 & 3.0 & 1.4 & 1.9 & 355 \\
\hline 1976 & Nyeri & 8.2 & 7.4 & 6.0 & 5.8 & 0.0 & 2.4 & 0.3 & 1.1 & 305 \\
\hline 1976 & Molo & 17.0 & 12.0 & 22.5 & 18.0 & 3.6 & 2.2 & 6.6 & 5.9 & 1110 \\
\hline 1976 & Ol Joro Orok & 9.8 & 5.3 & 13.1 & 11.9 & 1.0 & 0.4 & 2.9 & 3.2 & 1305 \\
\hline 1977 & Lanet $1 \mathrm{P} 1^{*}$ & 18.6 & 15.8 & 18.1 & 13.6 & 6.1 & 6.9 & 5.7 & 4.9 & 911 \\
\hline 1977 & Lanet 1 P2* & 17.0 & 13.8 & 17.0 & 11.7 & 5.6 & 6.3 & 4.3 & 3.4 & 851 \\
\hline 1977 & Lanet 1 P3* & 15.5 & 12.7 & 13.9 & 12.3 & 2.4 & 5.0 & 3.1 & 3.6 & 831 \\
\hline 1977 & Lanet 1 P4* & 13.1 & 11.1 & 10.9 & 10.9 & 1.4 & 4.6 & 2.7 & 3.6 & 760 \\
\hline 1977 & Lanet 1 P5* & 12.0 & 10.0 & 9.6 & 8.9 & 1.3 & 3.9 & 2.1 & 2.3 & 625 \\
\hline 1977 & Lanet 1 P6* & 10.0 & 8.5 & 8.0 & 8.0 & 0.3 & 3.0 & 1.2 & 1.2 & 615 \\
\hline 1977 & Lanet $2 \mathrm{P} 1 *$ & 14.9 & 12.9 & 13.0 & 12.4 & 2.6 & 4.9 & 4.9 & 4.3 & 825 \\
\hline 1977 & Lanet 2 P2* & 13.2 & 10.7 & 11.5 & 11.4 & 2.1 & 4.9 & 3.0 & 4.3 & 810 \\
\hline 1977 & Lanet 2 P3* & 13.9 & 8.7 & 11.1 & 8.5 & 1.7 & 4.1 & 3.2 & 3.0 & 740 \\
\hline 1977 & Lanet 2 P4* & 10.5 & 7.8 & 9.5 & 7.6 & 0.8 & 3.0 & 2.3 & 2.7 & 700 \\
\hline 1977 & Lanet 2 P5* & 9.2 & 7.7 & 7.5 & 7.2 & 0.1 & 3.0 & 1.5 & 2.2 & 670 \\
\hline 1977 & Lanet 2 P6* & 7.2 & 6.6 & 7.3 & 6.1 & 0.1 & 2.5 & 1.0 & 0.6 & 640 \\
\hline Mean & of 37 locations & 14.04 & 10.23 & 13.72 & 11.66 & 2.41 & 3.95 & 3.84 & 3.54 & 655 \\
\hline Mean & of 33 locations 1 & 14.27 & 10.53 & 13.12 & 11.15 & 2.43 & 4.24 & 3.49 & 3.25 & 593 \\
\hline
\end{tabular}

* P1 stands for first planting date, P2 for second, etc.

1 Excluded are the 4 locations where rainfall exceeded $1000 \mathrm{~mm}$. 

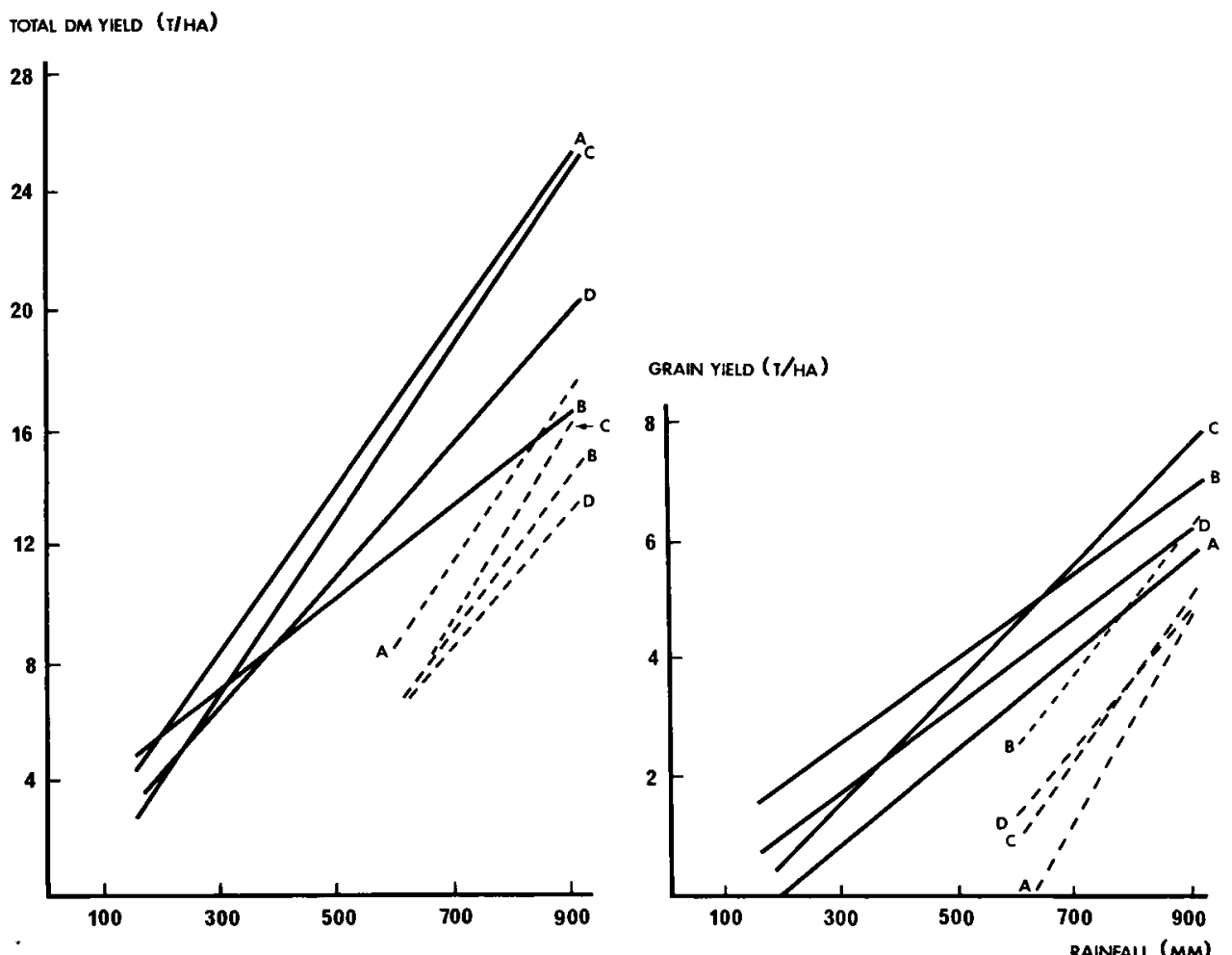

Fig. 1. Relation between rainfall and crop yields. Solid lines $=$ environments in group I; intermittent lines = environments in group II; $A=$ forage sorghum, B = grain sorghum, $\mathrm{C}=$ maize 'H 613', and $\mathrm{D}=$ maize 'Local Yellow'.

from Table 2. The yield reaction to rainfall variation was, on average, more pronounced in group II as compared to group I. This was particularly so for grain yield and less so for total DM yield. Apparently yields were more reduced if lower rainfall was combined with late planting than if only rainfall was lower, but planting was carried out at the start of the growing season.

Combining the data of group I and II in a single set of yield-rainfall regression lines would have provided a more useful and realistic model for yield predictions under practical farming conditions, because delayed planting is a normal phenomenon under such conditions. But such a model is not shown here because correlation coefficients were low, deviations from regressions high and, consequently, accuracy of prediction too low. Yield stability analysis where all the combined effects of the environment are taken into account partly compensates for this low accuracy, however.

The visual display of the yield stability analysis for environments with less than $1000 \mathrm{~mm}$ rainfall (i.e. group I and II) is shown in Fig. 2. For total DM yield it appeared that the forage sorghum was the highest yielding entry under 


\section{H. VAN ARKEL}

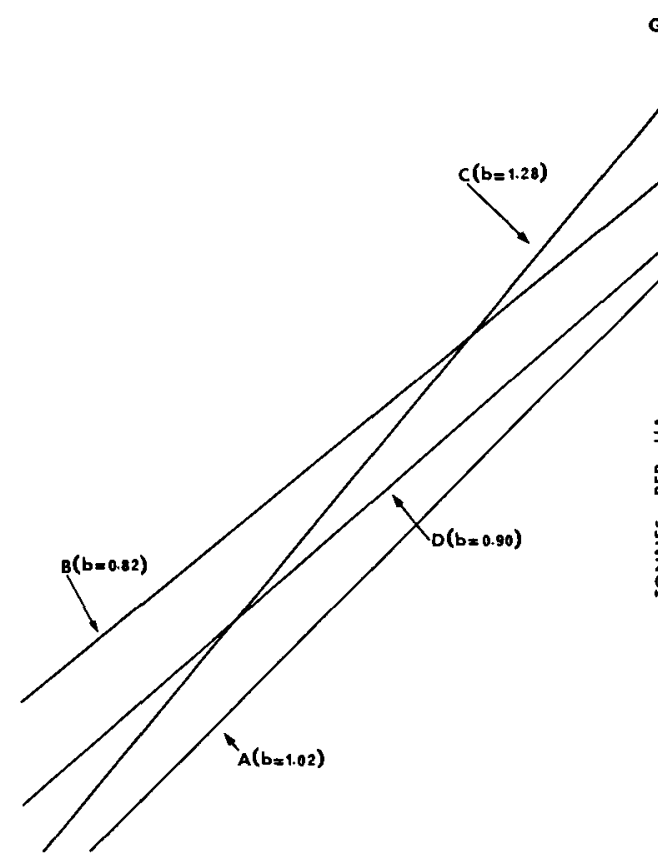

GRAIN YIELD
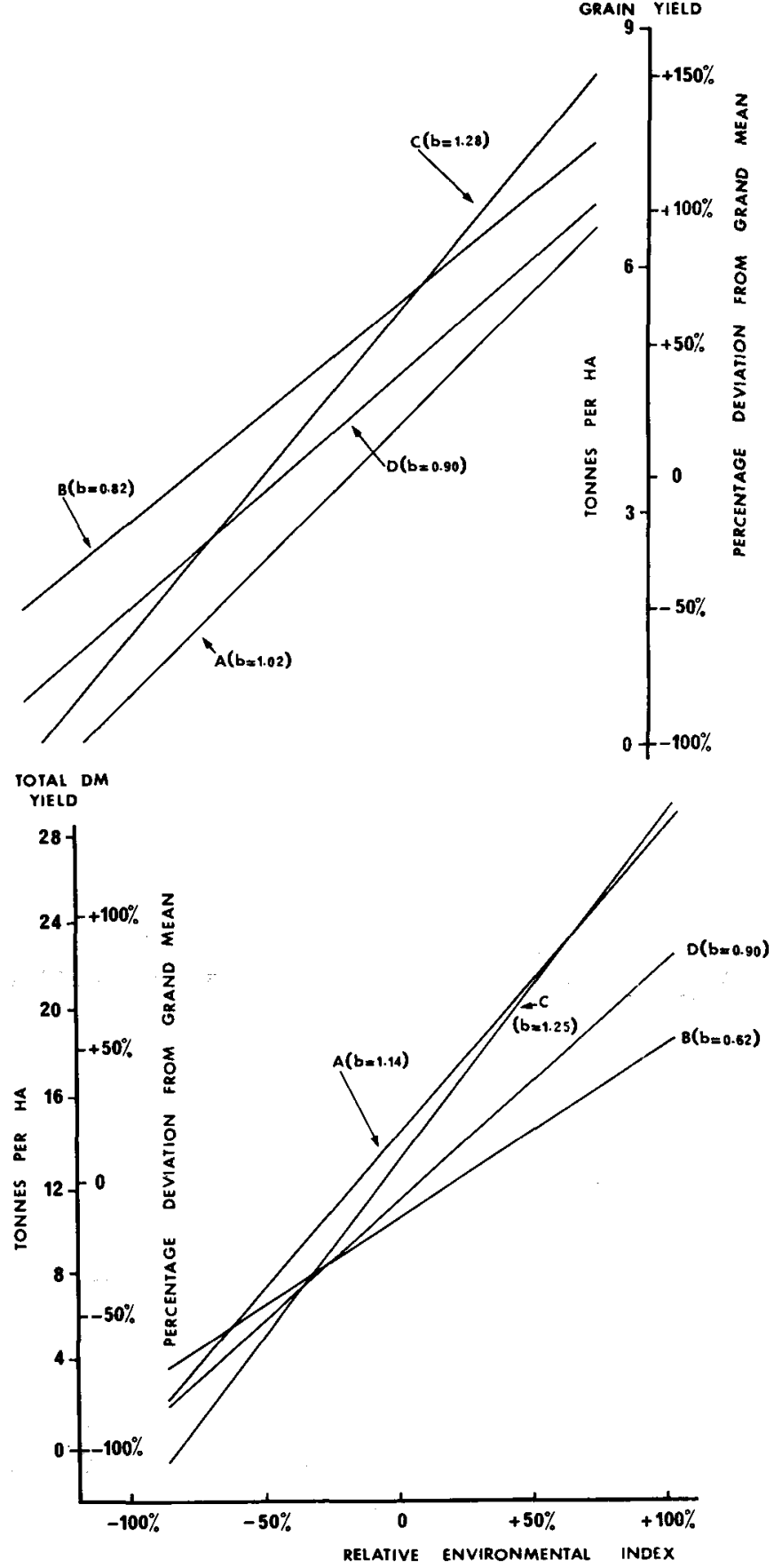

Fig. 2. Yield response to varying environments in the Kenya highlands. $b=$ regression coefficient; $\mathrm{A}=$ forage sorghum, $\mathrm{B}=$ grain sorghum, $\mathrm{C}=$ maize ' $\mathrm{H}$ 613', and $\mathrm{D}=$ maize 'Local Yellow'. 
Table 2. Regression coefficients for the relations yield on rainfall $1000 \mathrm{~kg} \cdot \mathrm{ha}^{-1} \cdot \mathrm{cm}^{-1}$ for early planted trials at locations with less than $1000 \mathrm{~mm}$ rainfall (Group I) and for the time of planting experiments (Group II).

\begin{tabular}{|c|c|c|c|c|c|c|}
\hline & \multicolumn{3}{|c|}{ Total DM yield } & \multicolumn{3}{|c|}{ Grain yield } \\
\hline & I & II & $\begin{array}{l}\text { increase of } \\
\text { II over I (\%) }\end{array}$ & $\mathrm{I}$ & II & $\begin{array}{l}\text { increase of } \\
\text { II over I (\%) }\end{array}$ \\
\hline Forage sorghum & 0.28 & 0.30 & 9 & 0.08 & 0.17 & 110 \\
\hline Grain sorghum & 0.16 & 0.25 & 61 & 0.07 & 0.13 & 73 \\
\hline Maize 'H 613' & 0.30 & 0.33 & 9 & 0.10 & 0.14 & 35 \\
\hline Maize 'Local Yellow' & 0.23 & 0.23 & 0 & 0.07 & 0.12 & 57 \\
\hline
\end{tabular}

Regression coefficients are rounded to two decimal places; this may result in small discrepancies with the figures for 'increase of II over I (\%)'.

most conditions. But if conditions became favourable there was a tendency for the maize hybrid to outyield the forage sorghum. Under very unfavourable conditions the grain sorghum became the highest yielding entry. For grain yield, the grain sorghum was the highest yielding entry under most conditions but maize ' $\mathrm{H}$ 613' was the better yielding entry under favourable conditions.

The patterns of lines in Fig. 2 are similar to those in Fig. 1, indicating that rainfall had a relatively large influence on the environmental index compared with other environmental influences. The difference between the two Figs. is mainly in the accuracy of the lines. Where in Fig. 1 the unexplained part of variation is large (approx. 50\%), in Fig. 2 less than 10\% of yield variation remained unexplained. This allowed significant differences between the four crops to be computed (Table 3). However, if the yield stability analyses were computed including the four yield data of group III, the unexplained variation sharply increased again mainly due to the reversed relation between rainfall and crop yields (analyses not shown). The similarity and difference between Figs. 1 and 2 and the reasoning for excluding group III from the yield stability analyses will be discussed in more detail below.

Table 3. Regression coefficients for genotype $\times$ environment interaction and mean yields of two sorghum and two maize cultivars. $\left(b=\right.$ regression coefficient; $s_{b}=$ standard error; $\mathrm{y}=$ mean yield).

\begin{tabular}{|c|c|c|c|c|c|c|}
\hline & \multicolumn{3}{|c|}{ Total DM yield } & \multicolumn{3}{|c|}{ Grain yield } \\
\hline & b & $\mathbf{s}_{\mathrm{b}}$ & $\mathrm{y}$ & b & $s_{b}$ & $\mathrm{y}$ \\
\hline Forage sorghum & $1.14 \mathrm{a}$ & 0.029 & $14.27 \mathrm{a}$ & $1.02 \mathrm{a}$ & 0.054 & $2.43 \mathrm{a}$ \\
\hline Grain sorghum & $0.62 \mathrm{~b}$ & 0.045 & $10.53 \mathrm{~b}$ & $0.82 \mathrm{~b}$ & 0.020 & $4.24 \mathrm{~b}$ \\
\hline Maize 'H 613 ' & $1.25 \mathrm{c}$ & 0.031 & $13.12 \mathrm{c}$ & $1.28 \mathrm{e}$ & 0.047 & $3.49 \mathrm{e}$ \\
\hline Maize 'Local Yellow' & $0.90 \mathrm{~d}$ & 0.043 & $11.15 \mathrm{~b}$ & $0.90 \mathrm{a}$ & 0.049 & $3.25 \mathrm{~d}$ \\
\hline
\end{tabular}

Regression coefficients and mean yields with the same superscript within one column are not significantly different at $P=0.05$. 


\section{Interaction between genotypes and environments}

The difference between the reaction of the four genotypes in total DM yield and grain yield production resulting from environmental differences can be seen from two aspects of Fig. 2. Firstly, from the range of the scale of the 'relative environmental index' which is covered; for total DM yield this varied from $-85 \%$ to $+105 \%$, whereas for grain yield, the index varied from $-95 \%$ to $+120 \%$. This shows that, in general, grain yields were more sensitive to environmental influences than total DM yields. Secondly, the regression coefficients can be compared (Table 3). It then appeared that both maize cultivars reacted similarly in total DM yield and grain yield on changes of the 'relative environmental index'. But the two sorghums reacted very differently. The forage sorghum with $b=1.14$ for total DM yield reacted favourably on increased values of the index, but this sorghum was not able to react equally favourable on improved conditions with regard to grain production $(b=1.02)$. The grain sorghum with $b=0.62$ for total DM yield reacted less favourably on improved environmental conditions than this sorghum did with regard to grain yield $(b=0.82)$. Maize ' $H$ 613' and the grain sorghum were the most unstable and most stable crop respectively, both for grain and for total DM yield. But the yield crossing point for these two cultivars occurred for grain yield under more favourable environmental conditions than for total DM yield (Fig. 2). This was because maize ' $\mathrm{H}$ 613' required an increasingly higher stover production compared with the grain sorghum to produce one extra unit of grain (Fig. 3).

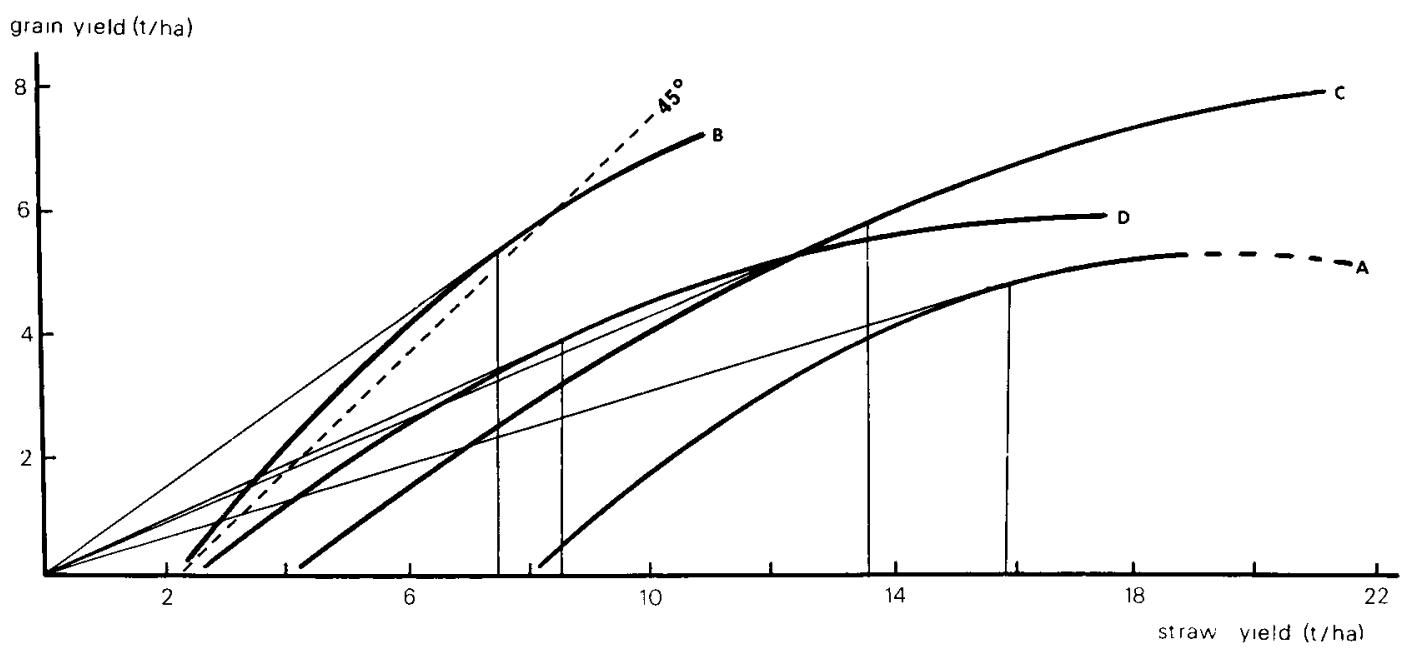

Fig. 3. Relation between straw yield and grain yield in group $\mathrm{I}$. $\mathrm{A}=$ forage sorghum, $\mathbf{r}=$ $0.79 ; \mathrm{B}=$ grain sorghum, $\mathrm{r}=0.97 ; \mathrm{C}=$ maize ' $\mathrm{H} 613$ ', $\mathrm{r}=0.96 ; \mathrm{D}=$ maize 'Local Yellow', $\mathrm{r}=0.95$. 


\section{Grain production efficiency}

The grain production efficiency is here expressed as a function of the specific water use for DM production and as a function of the DM distribution in the plant. The specific water use for DM production can be deduced from Fig. 1. This was done by dividing the $\mathrm{x}$ - co-ordinate over the $\mathrm{y}$ - co-ordinate of any point on a regression line, and some of the resulting values are shown in Table 4 . Not entirely unexpectedly, the most efficient sorghum had a lower specific water use than either maize $\mathrm{cv}$. The specific water use of the forage sorghum and maize 'Local Yellow' was fairly stable around 350 and 450 litres $\mathrm{kg}^{-1} \mathrm{DM}$ respectively. But for the two crops most interesting for grain production, i.e. the grain sorghum and maize ' $\mathrm{H}$ 613' the situation was different. The grain sorghum had a lower specific water use than the maize if rainfall was low. If rainfall increased the maize improved its specific use but the grain sorghum made less efficient use of the available water. The point where the specific water use of the two crops was the same was at about $300 \mathrm{~mm}$ rainfall. This indicates that the noted drought resistance of sorghum, in general, only led to a superior water use efficiency of the grain sorghum used here if rainfall was very low.

The superior grain yielding ability of the grain sorghum, over much of the range of conditions studied, appeared mainly due to the DM distribution. Fig. 3 shows that at any given level of straw production, which could be reached by all crops, the grain sorghum produced the highest amount of grain. The tangent from the origin to any point of the curves gives the grain/straw ratio of a crop. The grain sorghum had its maximum grain/straw ratio of 0.70 at a straw yield of $7800 \mathrm{~kg}$ $\mathrm{ha}^{-1}$ and at higher straw yield levels the ratio hardly declined. All other crops had the highest grain/straw ratio, which was always lower than of the grain sorghum, only at higher straw yields. If straw yields were higher than where the grain/straw ratio maximized, the ratios decreased more than with the grain sorghum. But some of the decrease may be due to the selection of the regression formula. The curves were forced in a quadratic model in such a way that the total squared deviations from regression were minimized. A questionable result of the selection of the formula, for instance, is the absolute decrease of grain yield at straw yields in excess of $19000 \mathrm{~kg} \mathrm{ha}^{-1}$ for the forage sorghum. It can also be seen that maize 'Local Yellow' had its maximum grain/straw ratio (0.47) at a lower straw yield

Table 4. Average specific water use for early planted crops (group I) in litres $\mathrm{kg}^{-1} \mathrm{DM}$ at different amounts of rainfall received during the growing season (derived by regression analyses).

\begin{tabular}{llllllll}
\hline & \multicolumn{3}{l}{ Rainfall $(\mathrm{mm})$} & & & & \\
\cline { 2 - 3 } & 200 & 300 & 400 & 500 & 700 & 900 \\
Forage sorghum & & & & & & & \\
Grain sorghum & 347 & 350 & 352 & 353 & 354 & 355 \\
Maize 'H 613' & 358 & 419 & 458 & 485 & 521 & 543 \\
Maize 'Local Yellow' & 491 & 424 & 396 & 381 & 365 & 357 \\
\hline
\end{tabular}


level than maize ' $\mathrm{H}$ 613' (0.42). This explains why the yield crossing point for these two maizes in Fig. 2 is at a higher yield level for grain yield than it is for total DM yield.'Local Yellow' only outyielded ' $H$ 613' in DM production under very severe environmental conditions. But, if harvested for grain there was a wider range of - unfavourable - conditions under which 'Local Yellow' outproduced ' $H$ 613'. This finding was in agreement with the widespread farmers opinion in Kenya.

With all four crops a higher grain yield was combined with a higher straw yield. From a comparison of the curves with the $45^{\circ}$ line in Fig. 3 it can be seen that, with the exception of the grain sorghum, all crops produced an increasingly higher amount of straw to achieve a certain grain yield increase. From the same figure it can also be estimated at what straw yield grain yield started. For the grain sorghum this was $2500 \mathrm{~kg} \mathrm{ha}^{-1}$ whereas this was $8000 \mathrm{~kg} \mathrm{ha}^{-1}$ for the forage sorghum. The maizes with 2600 and $4000 \mathrm{~kg}^{-1}$ occupied an intermediate position.

The relation between rainfall and grain/straw ratio is also a measure of the grain production efficiency (Fig. 4), although it incorporates much of what has been detailed on this subject above. All ratios initially increased with increasing rainfall and their maximum was estimated to be between $625 \mathrm{~mm}$ for the grain sorghum to $850 \mathrm{~mm}$ for the forage sorghum. At higher rainfall figures the ratios tended to decline, indicating that additional rainfall increased the straw yield relatively more than grain yield.

\section{Discussion}

Rainfall and temperature effects

Separating the yield data into three groups on the basis of time of planting and rainfall has been useful because within each group the rainfall-yield relation was

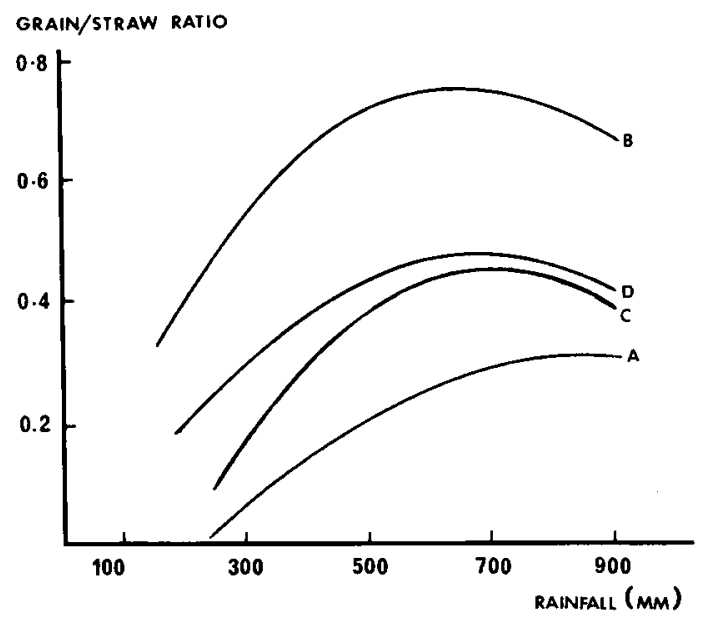

Fig. 4. Relation between rainfall and grain/straw ratio in group $1 . \mathrm{A}=$ forage sorghum, $\mathbf{B}=$ grain sorghum, $\mathrm{C}=$ maize 'H 613 ', $\mathrm{D}=$ maize 'Loca! Yellow'. 
different. It was shown that if rainfall was under $1000 \mathrm{~mm}$ the yield-rainfall regression was larger for late planted crops as compared to early planted crops. Furthermore, the positive yield-rainfall correlations as shown in Fig. 1 did not apply to environments where rainfall was above $1000 \mathrm{~mm}$ (Table 5). This table shows that yields were generally depressed if rainfall exceeded $1000 \mathrm{~mm}$. But particularly the yields of the sorghum were depressed, thus reversing the yield ranking order for sorghum and maize. It is questionable why the yields in group III were so different from what was to be expected on the basis of rainfall or average crop yield. Since there were only four trial sites in group III and since the environmental data collected were limited to rainfall, altitude and a few temperature data only, these yield reactions cannot be explained satisfactorily. Nevertheless, there are indications that differences between the reactions of sorghum and maize to temperature differences played a role.

Unpublished results of a preliminary trial carried out by the 'Department of field crops and grassland husbandry' in Wageningen support this theory. In a laboratory controlled experiment the growth of maize, the cold tolerant grain sorghum 'E 1291' and a normal lowland sorghum 'Serena' was followed under different temperature regimes from sowing up to the eight leaf stage. Although not conclusive in all aspects there was a clear tendency for maize to have a lower minimum temperature for germination than the cold tolerant grain sorghum. But the latter had a lower minimum germination temperature than the lowland sorghum. The speed of plant development after germination showed the same ranking order.

Increased rainfall reduces soil temperature through increased evaporation (Cooper, 1974). Therefore in group I higher rainfall was associated with lower temperatures. But in group II a lower rainfall i.e. later planting, was associated with lower temperatures. It is likely that these lower temperatures causec the crops in group II to show a stronger relation between rainfall and yield than the crops in group I (van Arkel, 1980). The theory that the sorghums are more sensitive to lower temperatures (i.e. late planting in group II) than maize is not disproved by the experiments reported here (Table 2). But the data in Table 2 do not convincingly suggest the existence of such a difference in temperature sensitivity, which is due to the wide variation of results.

The theory of different temperature sensitivities of sorghum and maize would

Table 5. Average DM yield and grain yield for environments with $800-1000 \mathrm{~mm}$ and above $1000 \mathrm{~mm}$ rainfall.

\begin{tabular}{|c|c|c|c|c|c|c|c|c|}
\hline & \multicolumn{4}{|c|}{ Total DM yield (1000 $\left.\mathrm{kg} \mathrm{ha}^{-1}\right)$} & \multicolumn{4}{|c|}{ Grain yicld (1000 kg ha-1) } \\
\hline & $\begin{array}{l}\text { forage } \\
\text { sorghum }\end{array}$ & $\begin{array}{l}\text { grain } \\
\text { sorghum }\end{array}$ & $\begin{array}{l}\text { maize } \\
\text { 'H 613' }\end{array}$ & $\begin{array}{l}\text { maize } \\
\text { 'Local } \\
\text { Yellow' }\end{array}$ & $\begin{array}{l}\text { forage } \\
\text { sorghum }\end{array}$ & $\begin{array}{l}\text { grain } \\
\text { sorghum }\end{array}$ & $\begin{array}{l}\text { maize } \\
\text { 'H 613' }\end{array}$ & $\begin{array}{l}\text { maize } \\
\text { 'Local } \\
\text { Yellow' }\end{array}$ \\
\hline $800-1000 \mathrm{~mm}$ & 22.0 & 15.5 & 21.3 & 16.8 & 4.7 & 6.3 & 6.3 & 5.3 \\
\hline$>1000 \mathrm{~mm}$ & 12.1 & 7.8 & 18.6 & 15.8 & 2.2 & 1.5 & 6.2 & 6.0 \\
\hline
\end{tabular}


explain or is supported by the deviating yields of the four environments in group III. Moisture deficiencies are unlikely to have played an important role here and consequently temperature is thought to have become relatively more important. During the first 35 days after emergence temperatures were 16.3, 15.4 and $15.0^{\circ} \mathrm{C}$ for Kitale, Molo and $\mathrm{O} 1$ Joro Orok respectively (no data for Baraton were available). This compares with $18.6^{\circ} \mathrm{C}$ for Lanet (average of Lanet 1 and 2, 1976, 1977). At Kitale the lower temperature was due to late planting associated with high rainfall and at Molo and Ol Joro Orok the low temperatures were the result of a higher altitude $(2593 \mathrm{~m}$ and $2410 \mathrm{~m})$ associated with more rain. It was not possible to find significant correlations between these temperatures and yields, but the trend agrees with what was found before. Temperatures at all four stations were lower than at Lanet and crop yields were lower than what would be expected on the basis of rainfall. This can be seen from Table 5 which compares the yields of crops grown under $800-1000 \mathrm{~mm}$ rainfall with the yields of crops grown under rainfall above $1000 \mathrm{~mm}$ and shows that most yields were lower at high rainfall. Fig. 5 shows that under high rainfall sorghum suffered relatively higher yield losses than maize. The yield reduction of the grain sorghum under colder conditions was even more pronounced if planted late under colder

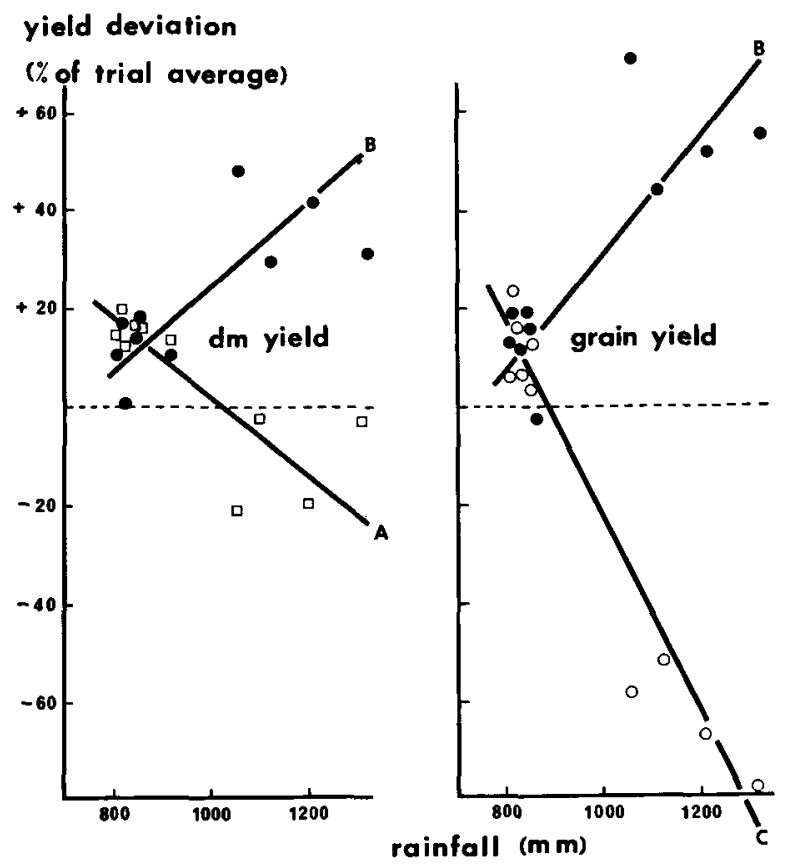

Fig. 5. Yield deviation of the highest yielding sorghum and maize from the trial yield average as affected by rainfall. $A=\square=$ forage sorghum, $B=\bullet=$ maize ' $H$ 613', $\mathrm{C}=\mathrm{O}=$ grain sorghum. 
conditions (at Kitale). Presumably because now also the soil in which the sorghum was planted had cooled down (van Arkel, 1980).

Although the yield of the grain sorghum was severely depressed at Kitale, it is striking that the grain sorghum suffered relatively less, if planted late under the more limited moisture conditions in the time of planting trials. It seems likely that the relatively higher temperature sensitivity of the grain sorghum as compared with the maizes was outweighed by its higher drought resistance. This conclusion changes the interpretation of the results of a previous study where the yield reduction due to late planting was correlated with temperature decreases only (van Arkel, 1980).

The fact that the poor performance of the sorghums under high rainfall conditions should not be attributed to rainfall per se is confirmed by a personal observation which showed that the same grain sorghum and forage sorghum $\mathrm{cv}$. grown with abundant irrigation under warm lowland conditions, performed very well.

There is internationally little known about the relation between temperature and plant development and growth of cold-tolerant sorghum. This is partly because high altitude cold-tolerant sorghums have been only recently identified as such. Standard textbooks still classify sorghum as a crop of hot and warm countries (e.g. Purseglove, 1972). But without fundamental temperature-growth data available it became clear a few years ago that high altitude sorghums were more cold-tolerant than lowland sorghums (van Arkel, 1977; Singh, 1978). These first findings triggered some more detailed work. Besides the above quoted work in Wageningen some interest arose in the USA where it is believed that a higher degree of cold tolerance may allow the cultivation of sorghum at higher latitudes. Eastin et al. (1976) found in growth chamber study that cold-tolerant cvs. had a 6 to $10{ }^{\circ} \mathrm{C}$ lower optimum temperature for maximum growth and a 20 to $25 \%$ higher respiration rate than cold susceptible sorghums. These results appear to warrant the term cold-tolerant. Some of the results from the experiments reported here indicate that the sorghums were not as cold-tolerant as maize. However, it is likely that there are cv. differences. A further identification and exploration of these differences is likely to produce material with a better cold-tolerance than the cvs. used here.

\section{Oxygen deficiencies and altitude effects}

The yield differences in this study have been related to rainfall and temperature and one may question the likelihood of oxygen deficiencies in the soil having played an important role. Allan (1972), without measuring soil air composition, indeed suggested that poor soil aeration was responsible for the lower yields of late planted maize. Giesler (1969) showed that the growth of both roots and shoots of maize was positively correlated with the $\mathrm{O}_{2}$ concentration in the soil air atmosphere up to $21 \% \mathrm{O}_{2}$. However, Cooper (1975) and Cooper \& Law (1977) found in a number of detailed growth studies under field conditions that there was no measurable decline in maize growth rates, even when $\mathrm{O}_{2}$ deficits went up as high as $6 \%$. They also showed this to be an unusually high oxygen deficiency 
level. Sorghum is known to withstand poor soil aeration better than maize (Purseglove, 1972). In Western Kenya sorghum is often planted in soils with inadequate drainage just for this reason. It is therefore concluded that at high rainfall environments the lower sorghum yields were not due to inadequate soil aeration.

Altitude was not related to crop yields either. This finding is in agreement with other work with maize in Kenya (Darrah \& Penny, 1974; Darrah, 1976). These authors reported no significant correlations between altitude and yield within the range of altitudes used here. But if all their data from sites ranging from sea level to 2700 in elevation were regressed on altitude the correlation was significant.

\section{The measure of the environment}

Yield differences in multi-locational crop testing are always due to a number of factors, e.g. genetic potential, rainfall, altitude, temperature, radiation, soil conditions and others. With the limited information available in this study it was not possible to adequately qualify the effects of each of those factors. It proved that rainfall alone already explained about $50 \%$ of the DM yield differences, and between 22 and $57 \%$ of the grain yield differences if all 37 sites were combined (Table 6). Subsequently the data from group III were excluded for reasons explained above and group I and II were regressed on rainfall both in a pooled and in two separate analyses. In the pooled analysis the explanatory value of rainfall did not consistently exceed the values obtained in the analyses with all 37 sites. But the regressions had become linear instead of quadratic.

Table 6. Percentages of total DM or grain yield variations explained by rainfall or environmental index if different sets of test environments were pooled. Group I = trials planted early and rainfall under $1000 \mathrm{~mm}$; Group II = time of planting experiment, rainfall under $1000 \mathrm{~mm}$.

\begin{tabular}{lllll} 
Rainfall & & & & $\begin{array}{l}\text { Environmental } \\
\text { index }\end{array}$ \\
\hline $\begin{array}{l}\text { all } \\
\text { sites }\end{array}$ & $\begin{array}{l}\text { group } \\
\text { I and II }\end{array}$ & group I & group II & group I and II
\end{tabular}

\begin{tabular}{llllll}
$\begin{array}{l}\text { Total DM yield } \\
\text { Forage sorghum }\end{array}$ & $50.1^{*}$ & 52.9 & 80.2 & 80.7 & 99.5 \\
Grain sorghum & $49.0^{*}$ & 59.7 & 83.6 & 87.4 & 90.8 \\
Maize 'H 613' & $51.9^{*}$ & 49.8 & 77.2 & 92.1 & 99.1 \\
Maize 'Local Yellow' & $53.9^{*}$ & 50.3 & 78.5 & 82.1 & 96.6 \\
& & & & & \\
Grain yield & & & & & \\
Forage sorghum & $22.0^{*}$ & 30.0 & 66.8 & 87.3 & 92.2 \\
Grain sorghum & $57.1^{*}$ & 63.0 & 81.8 & 83.8 & 89.6 \\
Maize 'H 613' & $38.0^{*}$ & 35.0 & 72.5 & 85.1 & 96.9 \\
Maize 'Local Yellow' & $52.2^{*}$ & 48.8 & 78.2 & 80.8 & 93.2 \\
\hline
\end{tabular}

* In these instances the quadratic regression component is significant. 
By separating the yield data from early planted crops and late planted crops, the explanatory value of rainfall for the prediction of yields was higher around $75 \%$ because this excluded the temperature-rainfall interaction. This shows that within group I and II rainfall explained more of the yield variation than any other environmental factor could have done. Indeed there is a great similarity in the patterns of the regression lines of Fig. 1 and those of Fig. 2, where all environmental factors have been taken into account. The difference between Figs. 1 and 2 is the accuracy of the regression lines. The environmental index in most cases explained well over $90 \%$ of the yield variation. But based on rainfall alone the 'factors of determination' were too low to be of practical value, in the sense of being able to accurately predict yield and, more important, cross-over points as shown in Fig. 1. To allow for all the combined environmental factors the 'environmental index' method proved a good tool.

Darrah (1976), who also used the yield stability analysis method for his regional maize yield trials, remarked that the method was very precise and allowed the yield of any genotype to be predicted quite accurately. This agrees with the work reported here, where correlation coefficients for genotype yield on environmental index (Fig. 2) were never below 0.95, indicating that at least $90 \%$ of all genotype yield variability was accounted for (Table 6). But the prediction is based on the value of the environmental index, which merely means that the yield of one genotype can be predicted accurately if the yields of all genotypes are known. But how can the yield be predicted before planting? This is particularly important around the cross-over point, where maize and sorghum reverse the yield ranking order. This cross-over point is not location specific and varies from year to year, depending on the weather and time of planting. Rainfall, however, was shown to account for only about half the variability of crop yield.

The few temperature data available indicated that temperature is also an important factor to be considered for the adaptation of sorghum and maize to different environments in the highlands. The data available did not allow precise yield-temperature regressions to be drawn. It must therefore be concluded that the best measure of the combined effects of all the relevant factors operating in the environments was provided by the genotypes themselves. This means that in areas where the yield potentials are not clear, some critical experiments will be needed to measure all the combined environmental influences.

\section{Yield differences between sorghum and maize}

The yields reported in this paper were all based on small plot trials which were carefully hand-harvested. It was shown (van Arkel, 1978a) that with mechanical harvesting, the forage sorghum had a considerable additional DM yield advantage over maize because the former can be harvested with only small losses, whereas the harvesting losses for maize are usually high. This proved particularly so if yield levels were high and when maize had lodged. This effect will result in a yield crossing point which occurs under more favourable conditions and therefore the sorghum would have a larger yield advantage over a larger range of environmental conditions. 
Further, the DM yields of the sorghums obtained at the Lanet 1 trial site (Table 1) agreed with those published earlier (van Arkel et al., 1977; van Arkel, 1978a). But the maize yields in those earlier papers were considerably lower than the maize yields reported here. This was partly due to heavy lodging in maize and with its associated harvesting losses. In anticipation of this lodging, plant populations for maize were kept at a sub-optimum level, whereas the plant populations in the small plot trials reported here were kept at a level where yields were expected to maximize. However, the lodging susceptibility of the maize is probably cultivar specific and it must be assumed that this can be improved through plant breeding efforts.

The superiority of the grain sorghum as compared with maize as a grain producer under drier conditions is based on its higher grain production efficiency. This was based, firstly, on a more favourable DM distribution in the plant at low and medium rainfall conditions and, secondly, on a higher water use efficiency of the sorghum under low rainfall conditions. Although superior to maize, the level of specific water use of the grain sorghum must be considered high (Arnon, 1972). This implies that there are likely possibilities of improving rainfall efficiency by improving rainfall penetration into the soil or by breeding for better adapted cultivars.

\section{Statistical analysis of yield differences}

The average yield differences between the four genotypes in group 1 plus 2 were small. Maize 'H 613' produced, on average, only $8 \%$ less DM than the forage sorghum, while the same maize hybrid under-produced the grain sorghum by $17 \%$ in terms of grain yield. However, the average yields of the four genotypes are not important for this study, because they depend largely on the distribution of test environments. If a relatively larger number of trial sites had been chosen in environmentally unfavourable areas, the yield advantages of the sorghums over the maizes would have been larger. By contrast, if more trial sites had been laid down in favourable growing areas, the maizes would have produced higher yield averages than the sorghums. The objective of this paper, however, was not to study actual yields but yield potentials. This is indepent of the distribution of trial sites over the various environmental conditions. It is therefore the interaction between genotypes and environments that is important (Fig. 2).

The differences between the regression coefficients (Table 3) were, in majority, only barely significant at the $5 \%$ probability level, despite their low variation coefficients. The probability levels for the differences between regression coefficients could have been increased by using the yield data of all three replicates to compute the environmental index, as proposed by Eberhart \& Russell (1966). Their method has been used frequently for the purpose of analysing regional crop trials, e.g. Majisu \& Doggett (1972), Darrah \& Penny (1974), Darrah (1976), Kofoid et al., (1977), and Francis et al., (1978). Unfortunately, the fundamenta! statistical assumptions do not appear to have been satisfied in any of this work, because the same yield data have been used to determine both the environmental index (independent variable) and the yields (dependent variables). The lines that 
have been drawn account for the observed results, but it is not valid to regard them as regression lines or to compare their slopes statistically (Freeman \& Perkins, 1971).

At the expense of precision it was, therefore, necessary to follow the method used in this paper. Another possibility would have been to use the yield data of all three replicates of one genotype as the base for the environmental index and to regress the average of the three replicates of each of the other three genotypes on it. This method which can be useful (van Arkel, 1980) did not prove satisfactory in the analysis of the data reported here.

\section{Acknowledgements}

Grateful thanks are offered to the Government of Kenya, UNDP and FAO for providing funds and facilities. I am grateful to the staff of the Beef Research Station for assisting with the field work. This paper is published with the permission of the Director of Research of the Ministry of Agriculture, Nairobi.

\section{References}

Allan, A. Y., 1972. The influence of agronomic factors on maize yields in Western Kenya, with special reference to time of planting. Ph. D. Thesis. Univ. of East Africa.

Arkel, H. van, 1977. New forage crop introductions for the semi-arid highland areas of Kenya as a means to increase beef production. Neth. J. agric. Sci. 25: 135-150.

Arkel, H. van, 1978a. The forage and grain yield of sorghum and maize as affected by soil moisture conservation, lodging and harvesting losses. Neth. J. agric. Sci. 26: 181-190.

Arkel, H. van, 1978b. Fertilizer response of cold-tolerant sorghums under semi-arid high altitude conditions. Neth. J. agric. Sci. 26:312-325.

Arkel, H. van, 1978c. The ratoon yield of cold tolerant sorghums. FAO KEN/76/020. Field document No. 7.

Arkel, H. van, 1979. Weed control in cold tolerant sorghums. Trop. Agric. (Trinidad) 36(2): 105-113.

Arkel, H. van, 1980. The forage and grain yield of cold-tolerant sorghum and maize as affected by time of planting in the highlands of Kenya. Neth. J. agric. Sci. 28: 63-77.

Arkel, H. van, M. J. Creek \& H. A. Squire, 1977. Cold tolerant sorghums: a spectacular forage crop for specific tropical applications. World Rev. Anim. Prod. 13(3): 75-80.

Arnon, I., 1972. Crop production in dry regions. Vol. I. Background and Principles. Leonard Hill Book Co., London.

Cooper, P. J. M., 1974. Soil temperature under maize and bare fallow in Western Kenya. 5th E. Afr. Cereals Res. Conf. Malawi.

Cooper, P. J. M., 1975. Studies on the soil atmosphere composition under maize, grass and bare fallow in Western Kenya. E. Afr. agric. For. J. 40: 313-331.

Cooper, P. J. M. \& R. Law, 1977. Soil temperature and its association with maize yield variations in the Highlands of Kenya. J.agric. Sci., Camb. 89: 355-363.

Darrah, L. L., 1976. Altitude and environmental responses of entries in the 1972-73 Eastern African maize variety trial. E. Afr. agric. For. J. 41: 273-288.

Darrah, L. L. \& L. H. Penny, 1974. Altitude and environmental responses of entries in the 1970-71 East African maize variety trial. E. Afr. agric. For. J. 40: 77-88.

Eastin, J. D., I. Brooking \& A. O. Taylor, 1976. Influence of temperature on sorghum respiration and yield. Agron. Abstr. p. 71. 
Eberhart, S. A. \& W. A. Russell, 1966. Stability parameters for comparing varieties. Crop Sci. 6: 36-40.

Enserink, H. J., 1976. Potential forage crop production in Kenya. M. Sc. Thesis. Agric. State University, Wageningen.

Finlay, K. W. \& G. N. Wilkinson, 1963. The analysis of adaptation in a plant breeding programme. Aust. J. Agric. Res. 14: 742-754.

Francis, C. A., M. Prager \& D. R. Laing, 1978. Genotype environment interactions in climbing bean cultivars in monoculture and associated with maize. Crop Sci. 18: 242-246.

Freeman, G. H. \& J. M. Perkins, 1971. Environmental and genotype environmental components of variability. Heridity 27: 15-23.

Giesler, G., 1969. Effects of oxygen and carbon dioxide concentrations in soil air on root and shoot growth in winter barley, maize and pea. Bayer Jb. London 46: 259-278.

Kofoid, K. D., W. M. Ross \& R. F. Mumni, 1977. Yield stability of random-mating populations. Journal Series, Nebraska Agric. Exp. Stn Project No 12-009.

Majisu, B. N. \& H. Doggett, 1972. The yield stability of sorghum varieties and hybrids in East African environments. E. Afr. agric. For. J. 38: 179-192.

Purseglove, J. W., 1972. Tropical crops: Monocotyledons. Longman, London.

Sheldrick, R. D., 1974. Evaluation of maize as a forage, Kitale 1968-73. Technical Report No 2, National Agricultural Research Station Kitale, Kenya.

Singh, S. P., 1978. Breeding grain sorghum for cold tolerance. CIMMYT, Londres 40, Mexico 6 DF, Mexico.

Yates, F. \& W. G. Cochran, 1938. The analysis of groups of experiments. J. Agric. Sci. 28: 556-580.

Zar, J. H., 1974. Biostatistical analysis. Prentice-Hall Inc., Englewood Cliffs, NJ. 